\title{
The realization path of shared packaging design in the era of sharing economy
}

\author{
Dai xuehong $^{\dagger 1,}$, Yao xingyu ${ }^{1, b}$ \\ ${ }^{1}$ Visual and information Design Jiangsu University Jiangsu, China
}

\begin{abstract}
With the development of express industry, express packaging has caused huge environmental pollution and serious waste of resources. "New plastic restriction order" and "Express Green Packaging" put forward that green management of express packaging has become an important ecological civilization thought. According to the concept of recyclable development, sharing packaging design mode has become an effective way to achieve. As an effective governance path, it is of great social value to explore green packaging consumption, shared packaging structure and sharing mode. Based on the concepts of green environmental protection and green shared packaging design, the design path of shared packaging in the era of sharing economy is proposed.
\end{abstract}

\section{Introduction}

E-commerce mode has accelerated the production of a large number of express packaging. "In 2019, the business volume of express service companies was 63.52 billion, a year-on-year increase of $25.3 \%$, and the express business volume exceeded 60 billion pieces."[1] Express is an important part of the express delivery industry. Express packaging runs through in the entire circulation process of express transportation, storage, loading and unloading, sorting and distribution, it plays an important role in protecting commodities, facilitating logistics and transportation, promoting sales, and conveying information.[2] While express packaging brings convenience to people's lives and creates economic value, it also causes a lot of resource consumption and environmental pollution to the society. On January 19,2020, the National Development and Reform Commission announced the "Opinions on Further Strengthening the Treatment of Plastic Pollution" (hereinafter referred to as the "Opinions"). According to the guiding ideology of the "Opinions," and in accordance with the general idea of "banning one batch, replacing one batch, and standardizing a batch", it is required to prohibit and restrict the production, sales and use of certain plastic products, and to promote green, environmentally friendly and economically applicable plastic products and alternative products, regulate the recycling of plastic waste, and effectively control plastic pollution. Special emphasis is placed on emerging fields such as e-commerce and express delivery, forming a batch of replicable and extendable plastic reduction and green logistics models. On June 22, 2020, the State Post Bureau issued a notice of the "Green Packaging Standards for Express Mail" (hereinafter referred to as the "standards"), requesting the

a574100755@qq.com

b178264234@qq.com promotion of green governance of express mail packaging promoting resource conservation and utilization, and reducing environmental pollution. Adhering to the concept of green packaging design and forming the idea of sustainable development are currently urgent problems to be solved. Based on the idea of promoting green environmental protection and green packaging design, this paper proposes the concept of shared packaging design in the era of sharing economy to solve the current environmental pollution and waste of resources, further improve the shared packaging management system, and propose a feasible shared packaging realization path.

\section{Shared packaging design concepts and ideas}

\section{1 "Sharing economy" new business format promotes shared packaging design concepts}

The current evolution of social economic models and economic formats has promoted the emergence of new formats of the sharing economy. "It focuses on the consumer demand in the era of market economy. Through the development of the Internet and mobile technology, it can achieve high-efficiency synergy and matching of supply and demand. The competition, cooperation, innovation and creation of market participants emphasize the in-depth coordination and cooperation between individuals, and mobilize the participation of the whole society to pursue the maximization of the overall goal (ie $1+1>2$ or $2+2=5)$ in the sense of a new economic format."[3] The concept of shared packaging comes from the sharing economy (or sharing economy), and the sharing economy contains huge business opportunities. According to PricewaterhouseCoopers (2015),"the global 
sharing economy the scale will reach 335 billion U.S. dollars in 2025."[4] Botsman defines the sharing economy as "an economic model that shares idle resources such as space, skills, and goods for monetary or non-monetary gains."[5] The sharing economy is The pursuit of returns is "an emerging business phenomenon that has emerged with the development of the Internet."[6] Therefore, the sharing economy can be defined as "based on the Internet platform, individuals or organizations will limit the shortterm lease of resources to obtain profits. "[7] The generation of the shared packaging business model is based on innovative designs under the sharing economy model.

\subsection{Design concept of shared packaging business model}

The sharing economy includes producers, consumers, Internet platforms, etc. The core of the sharing economy is to exchange idle resources for benefits, while optimizing resource allocation, and further creating valuable service forms for idle resources. It includes the concept of sustainable development and promotes the format of the new economy. The design concept of shared packaging is based on this foundation, it is mainly based on the Internet platform, transfer the right to packaging in a short-term time, and uses a sustainable shared design model to implement a new business sharing model to achieve ecology and economy benefit (Figure 1). First, through the sharing platform, merchants and express companies will rationally optimize the allocation of idle resources, improve the utilization rate of packaging resources in the logistics industry, use the data platform to track "shared packaging" in real time, build a recycling system, and form effective information Sharing the Internet; secondly, constructing an object-oriented countercurrent system. Use the material reverse flow system to regain the use value of packaging or reprocessing, containers, packaging materials and related information used for commodity transportation, and flow them from the supply chain along the supply chain channels to the corresponding nodes at the same time. In the process of considering packaging recycling, the principles of reverse logistics standardization design are realized through standardization, energy saving, and material saving. Third, under the national implementation of green logistics and green packaging design concepts, use the big data platform, merchants, logistics Express companies and other companies jointly promote shared express packaging, the two parties jointly optimize and coordinate the concept of sustainable development, strengthen the green packaging management responsibilities of merchants and express companies, promote green packaging supply chains, and formulate alternative implementation plans such as one-time packaging reduction and recyclability, And carry out publicity and promotion, guide consumers' green consumption behavior, realize the new business model of shared packaging consumption recognition and practical support, and realize the function of green environmental protection.

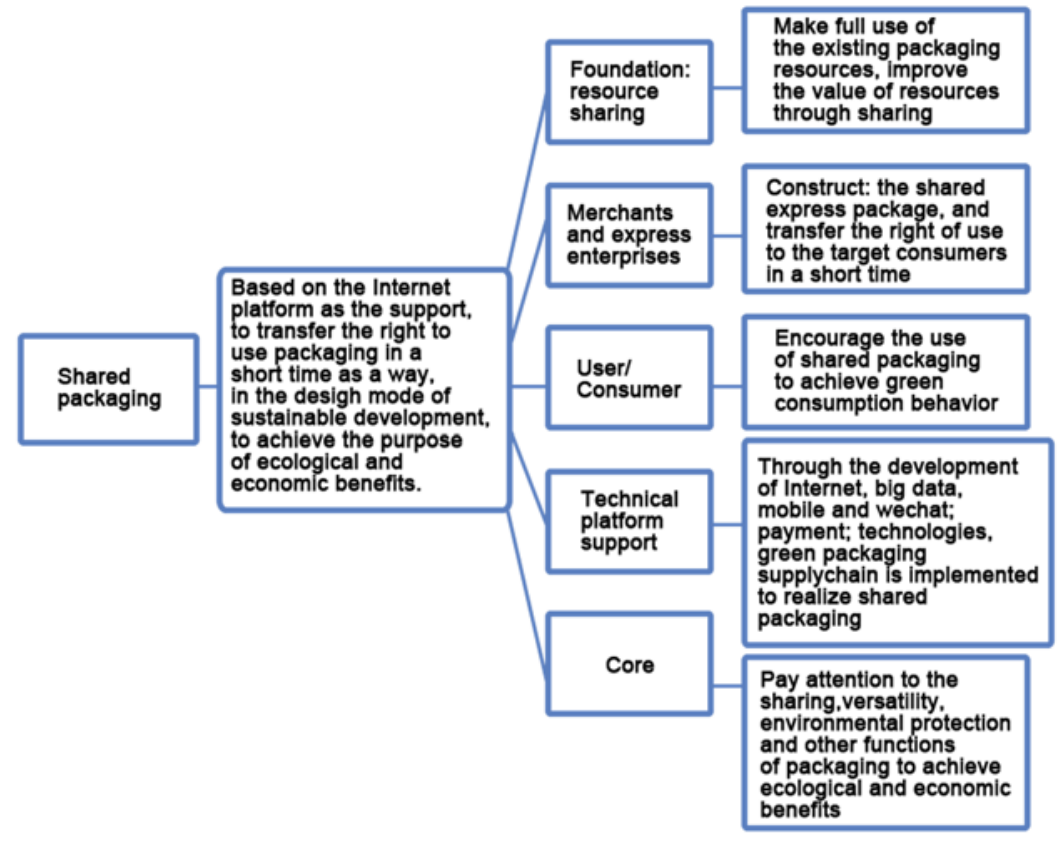

Figure 1: Model of shared packaging economy

\section{The dilemma of the new business model of shared packaging}

As a green business model, the sharing model of shared packaging is based on the concept of sharing packaging resources to achieve sustainable development, and the principle of co-construction and sharing to achieve ecological and economic dual benefits. In the era of the Internet and big data, how to promote consumers' sustainable consumption behavior, further improve reverse logistics technology and the sharing of packaging 
structure are still current dilemmas.

(1) How to promote green packaging consumption. Green consumption is also called "sustainable consumption", which refers to various consumption behaviors and consumption methods that start from meeting ecological needs, take health and protection of the ecology as the basic connotation, and comply with human health and environmental protection standards. This mode of consumption includes not only green products, but also the recycling of packaging boxes, the effective use of energy, and the protection of the environment. Sustainable consumption is a kind of moderate consumption, which promotes consumers to use shared packaging to promote low-carbon consumption, realize the recycling of packaging boxes, extend the use times and life of packaging boxes, and reduce carbon emissions. From the perspective of sharing, on the basis of sustainable development, how can shared packaging raise consumers' environmental awareness, promote consumers to use universal and shared packaging, establish a new concept of modern civilization, and implement green-based consumption mode is One of the issues that need attention in the sharing economic age.

(2) How to improve reverse logistics technology. With the strengthening of green packaging and environmental protection awareness, the economic value of reverse logistics has gradually emerged. Reverse logistics is different from the acquisition, recycling and reuse of waste products in the traditional logistics system. It is the research and promotion of new resource recycling technologies to reduce the finished products of the recycled materials. While considering the cost reduction, the use of reverse logistics may mean economic, social, and environmental benefits because it can bring about resource savings. Due to the late proposal of reverse logistics technology, the recycling and processing techniques are not mature, and there are few successful examples in actual use. The construction of reverse logistics logistics network, reverse information system and operation management system still needs to be improved. At the same time, it is still in the static investigation of a single package, and the research on the dynamic situation and type of standardized structure of shared packaging for versatility and sharing is relatively scarce. Therefore, how to use the characteristics of the sharing mechanism to strengthen upstream and downstream collaboration, avoid resource waste and environmental pollution, provide multiple recyclable packaging functions, and reduce the environmental cost, logistics cost and recycling cost of individual packaging for a single use, so as to achieve the design effect of packaging reduction and green need to be further improved.

(3) How to realize a shared packaging structure. Shared packaging is the physical carrier for the realization of recycled logistics. While laying a solid foundation for the sharing of resource information and improving the efficiency of transportation and transshipment, the packaging box material, structure, specifications, dimensions, quality and other properties need to be standardized design. On the basis of sharing mechanism platform, how to realize low-carbon packaging materials, repeated recycling of packaging, structure sharing of the same type of product packaging, simple visual style and integrated form, standardization of specifications, visual standardization and visualization of structure need further attention.

\section{The realization path of shared packaging}

\subsection{Promote green consumer behavior}

Green packaging means that it does not harm the environment, and the packaging needs to be produced from the entire life cycle of packaging materials, production processes, transportation processes, actual consumption processes and product disposal processes. Green consumption refers to "consumers consider the impact of their actions on the environment when purchasing, using or disposing of products, and try to minimize negative impacts and maximize long-term benefits."[8] Correspondingly, the green consumption behavior is the subjective and objective use of environmental protection, recyclable packaging boxes. Green consumption behavior is beneficial to the environment for all. Green consumption behaviors such as recycling and reuse involve consumers' self-control and measurement, as well as the impact of recycling and reuse of packaging bags on the environment and society. From a sharing perspective, the factors that affect consumers' green consumption behavior include consumer factors, external factors, and packaging material factors (Figure 2). Consumer factors are mainly concerned with the impact of consumers' values, standards, attitudes, etc. on consumers' green consumption. Starting to use environmental protection values increases consumers' attention to green packaging consumption information, and then chooses friendly packaging to increase consumers' selfresponsibility, enhances consumers 'preference for green packaging and enhances the information of perceived effectiveness on green packaging; External factors need to implement sustainable development for consumers based on environmental factors, such as economic considerations, supporting facilities and social norms. Economic considerations are to realize the effective use of shared packaging and save consumers' costs; supporting facilities are a series of convenient methods such as equipment and operating procedures for sharing platforms; Social norms generate green consumption behaviors through propaganda and education of consumers, making consumers passive accept the formed " conformity" consumption behavior, persuade consumers to accept the green consumption mode required by the society, and guide consumers to reduce the use of single packaging and use recycled packaging boxes. This type of consumption needs to "target consumers with different psychological control sources, and need to adopt differentiated implementation, whether the recycling behavior is convenient, time-consuming, etc., have a significant impact on residents' garbage recycling behavior;"[9] In the selection of materials, low-carbon materials are considered as the main direction of design, "the low- 
carbon design of packaging is based on the characteristics of the packaging itself, and the goal of rationalization, simplification and deep beautification is to further promote the construction of a resource-saving and environment-friendly society."[10]The selection of lowcarbon packaging materials makes full use of renewable resources. These materials reduce production costs while embodying a circular economy model. For example, PP (polypropylene), PE (polyethylene) and other recyclable packaging materials, due to their high-strength mechanical properties and good high wear-resistant processing performance, through the design of foldable, reusable packaging containers, customized for the management of recycling packaging lease,economical and environmentally friendly, easy to operate, easy to store items, and can achieve RFID intelligent tracking. In view of this, attention to consumer factors, external factors, and materials has positive significance for sustainable consumption behavior. Its essence is sustainable consumption behavior that conforms to consumers' psychological expectations and costs, thereby effectively reducing barriers to green consumption perception.

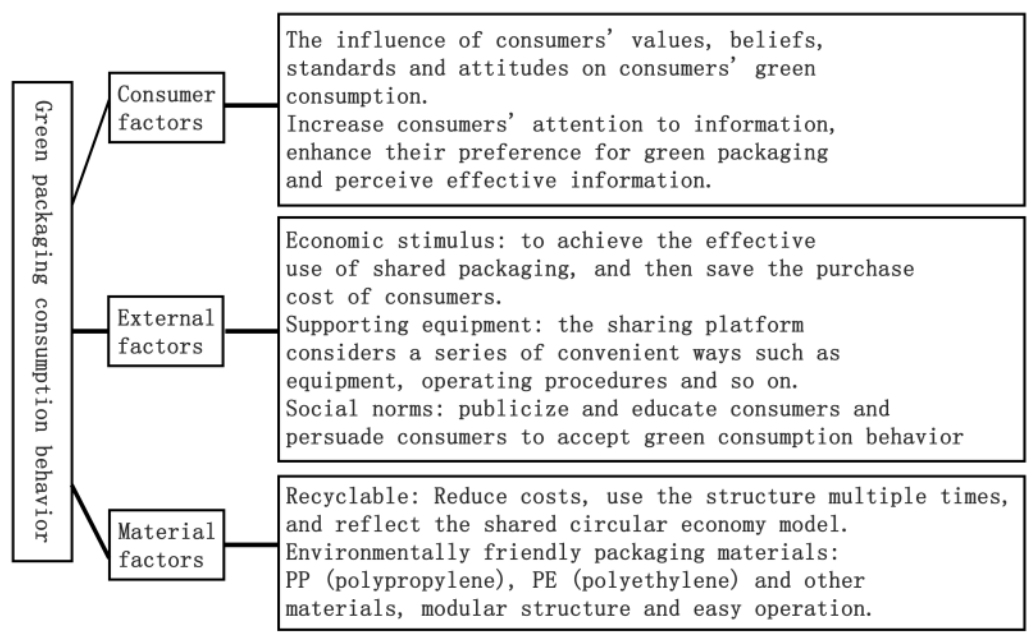

Figure 2: Promote green consumer behavior

\subsection{Sharing of packaging structure}

Shared packaging needs to meet multiple cycles of use, and structure classification design according to product characteristics, attributes, etc., to achieve sharing and sharing. Modularization can be adopted for different product characteristics and shapes, especially the shape or size of special-shaped objects, modular methods can be adopted, focusing on the essentials of fine packaging of internal parts, and ensure sustainable design principles that are quantifiable, measurable, foldable, and universal.

First, the structure is reasonable. The shared packaging box structure should be convenient for production, storage, transportation, use, etc. The quality and volume of the packaging container during storage and transportation should be considered for convenient transportation and stacking; secondly, the packaging structure should prevent excessive packaging, and the design should consider the void ratio of the packaging box., Size, etc., for the use of express packaging boxes for postal companies, "the appropriate type of packaging box should be selected according to the maximum quality and maximum integrated internal size of the contents," (Table 1) [11] and according to the actual contents of the box Structural design. In addition to the size set to meet the requirements of the "Specifications", a variety of packaging structure forms should be set for consumers to choose. The stacking of multiple packaging should adopt a standardized shape to meet the requirements of shared logistics packaging and make full use of space Rate and reduce waste of space. At the same time, the structure is easy to disassemble and convenient for consumers to use. The bottom or sealing of the shared packaging box should be automatically locked as much as possible (Figure 3). This kind of lock can automatically return to the locked state, which is extremely convenient to use, saves time and effort, and It has good bearing capacity and is suitable for automated production. It can also carry high-weight items and can be reused. At the same time, it should be considered that the packaging can be folded for multiple uses without occupying storage space (Figure 4). Second, the use of suspended fastening packaging. Suspended fastening packaging is a kind of internal packaging, mainly composed of corrugated paper and special film with strong friction, high elasticity and not easy to slide. It uses the least material to provide the protection, reuse, and space saving required by the product during transportation., Can reduce the use of fillers. The suspended fastening packaging structure is simple in design, that is, bend the side wings of the paper card upwards, loosen the fastening film, put the product between the film and the paper card, and then bend the side wings of the paper card downwards to tighten the fastening film, The product is securely fixed on the paper card, the fastened packaged product is embedded in the box, and the fixed product can be transported. This kind of packaging can use the transparency of the film to visually display the product and provide a product appearance display effect (Figure 5). Third, the modular structure of the unit. Shared express packaging can consider the structure of easy disassembly and installation, realize the modular structure of the unit, 
in line with the ergonomic design, this kind of container is durable, small in return, economical and environmentally friendly, easy to operate, easy to store items, and can realize RFID Smart tracking, etc. (Figure 6)

Table 1: Selection of packing box model of contents used by postal companies

\begin{tabular}{|c|c|}
\hline $\begin{array}{l}\text { Packing box } \\
\text { size }\end{array}$ & $\begin{array}{l}\text { Packing box model selection of the contents of the } \\
\text { postal company }\end{array}$ \\
\hline 1 & $\begin{array}{l}\text { The maximum mass of the contents in the No. } 1 \\
\text { packing box is } 3 \mathrm{~kg} \text {, and the maximum integrated } \\
\text { internal dimension is } 450 \mathrm{~mm} \text {; }\end{array}$ \\
\hline 2 & $\begin{array}{l}\text { The maximum mass of the contents in the No. } 2 \\
\text { packing box is } 5 \mathrm{~kg} \text {, and the maximum integrated } \\
\text { internal dimension is } 700 \mathrm{~mm} \text {; }\end{array}$ \\
\hline 3 & $\begin{array}{l}\text { The maximum mass of the contents in the No. } 3 \\
\text { packing box is } 10 \mathrm{~kg} \text {, and the maximum integrated } \\
\text { internal dimension is } 1000 \mathrm{~mm} \text {; }\end{array}$ \\
\hline 4 & $\begin{array}{l}\text { The maximum mass of the contents in the No. } 4 \\
\text { packing box is } 20 \mathrm{~kg} \text {, and the maximum integrated } \\
\text { internal dimension is } 1400 \mathrm{~mm} \text {; }\end{array}$ \\
\hline 5 & $\begin{array}{l}\text { The maximum mass of the contents in the No. } 5 \\
\text { packing box is } 30 \mathrm{~kg} \text {, and the maximum integrated } \\
\text { internal dimension is } 1750 \mathrm{~mm} \text {; }\end{array}$ \\
\hline 6 & $\begin{array}{l}\text { The maximum mass of the contents in the No. } 6 \\
\text { packing box is } 40 \mathrm{~kg} \text {, and the maximum integrated } \\
\text { internal dimension is } 2000 \mathrm{~mm} \text {; }\end{array}$ \\
\hline 7 & $\begin{array}{l}\text { The maximum mass of the contents in the No. } 7 \\
\text { packing box is } 50 \mathrm{~kg} \text {, and the maximum integrated } \\
\text { internal dimension is } 2500 \mathrm{~mm} \text {; }\end{array}$ \\
\hline
\end{tabular}
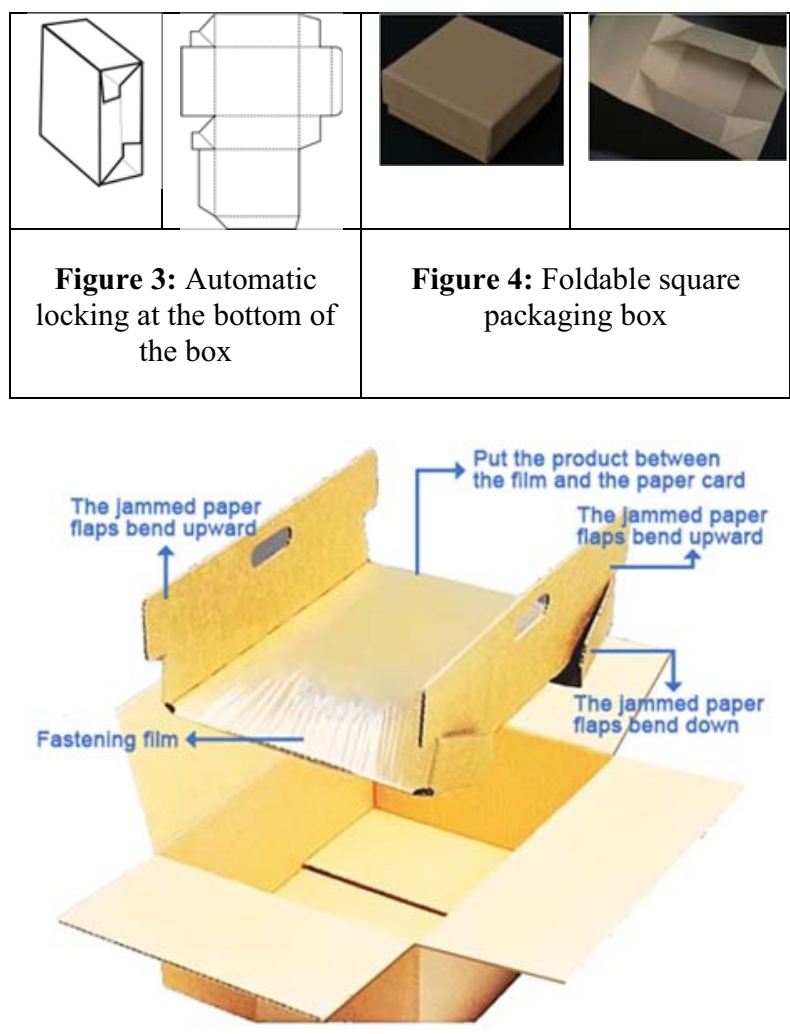

Figure 5: Fastening packaging

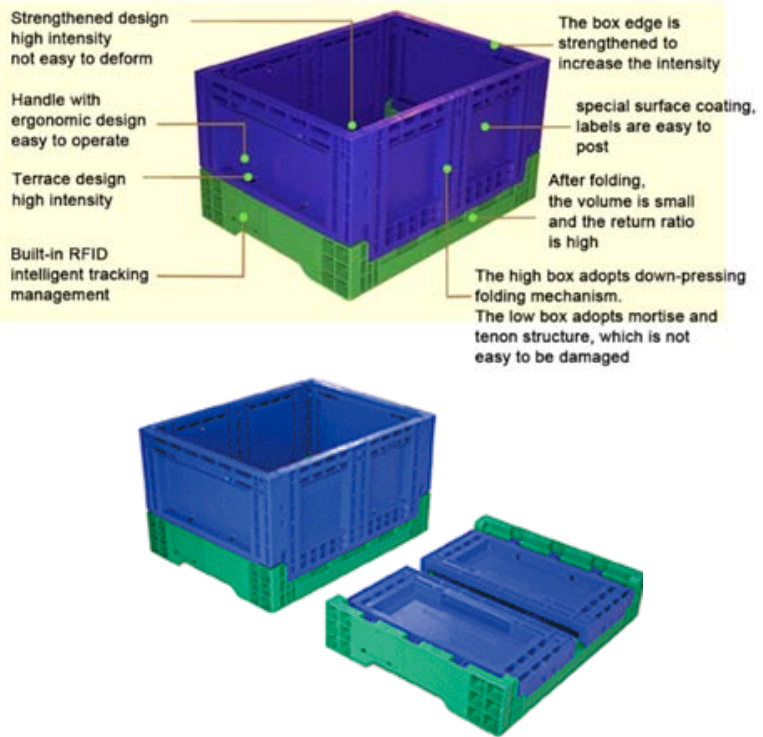

Figure 6: Foldable (modular structure) small recycling shared packaging image source http://www.lels.com.cn/biaozhunkltfpcchanpin/

\section{3 "Share+" Green Operation Mode}

Shared packaging is a "sharing +" operating mode that enables express companies, express companies and thirdparty agencies to establish a recyclable packaging sharing platform in accordance with the principles of coconstruction, sharing, and mutual benefit, and use sharing mechanisms to expand the scope of recyclable packaging applications, improve the resource utilization rate of packaging, and achieve green environmental protection. The operation mode of sharing + builds a recyclable packaging operation mode, an integrated recycling system for commodities and logistics, creates a "one box with multiple uses" packaging resources and a new operation mode of sharing economy. According to his / her geographical location, the user calls the nearest idle box resources, and according to his needs, the third-party logistics closest to the collection point is indicated by the sharing platform to provide the logistics box. Therefore, through the operating mechanism of the shared platform, the logistics mode can be better promoted, the green packaging supply chain can be strengthened, and the waste of packaging resources generated in the logistics process can be reduced, and the commonality, commonality, and environmental protection of shared express packaging can be realized. Using the shared information built by Internet, the shared packaging is fully displayed on the data platform in visual form such as graphics and text, so that consumers can accurately select the target requirements. On the one hand, an effective shared box management system (Figure 7) is established to monitor the recovery, testing, classification and remanufacturing of the packaging boxes to ensure the accuracy of the information of the recycling boxes. On the other hand, it can allow express companies to grasp the relevant information of shared packaging in real time by using intelligent positioning systems. And then realize the high efficiency of shared packaging supply chain management. Generally 
speaking, packaging information is shared through RFID radio frequency cards, AR augmented reality technology applications, and QR code scanning.

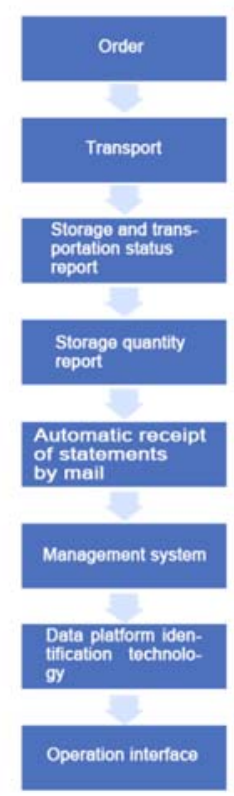

Figure 7: Shared box management system

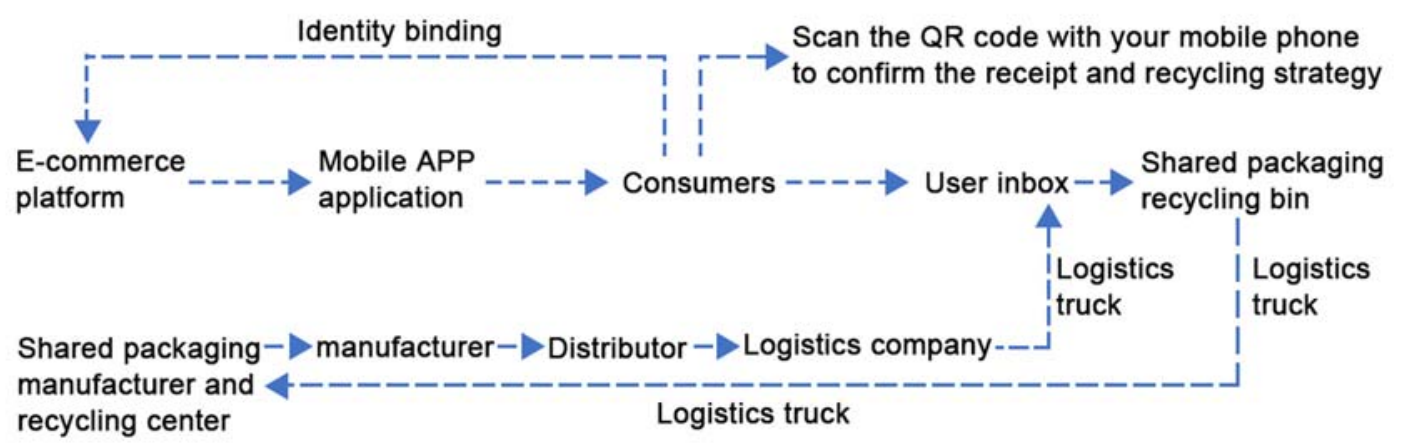

Figure 8: Shared express packaging operation business model

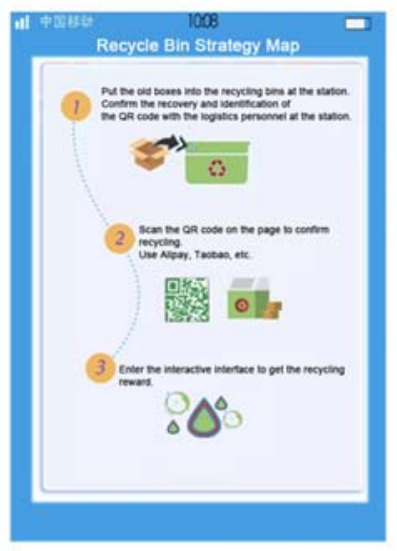

Figure 9: Recycling, recycling and strategy diagram of old express packaging

As shown in Figure (8), it is the operating model of shared express packaging business. Through the design of the APP mobile phone application rental model, the use of e-commerce platform for manufacturers, consumers and other manufacturers to provide recyclable, intelligent express packaging rental model, to achieve the sustainable development and sharing form of green packaging. The main process is based on the e-commerce platform. Consumers use the mobile phone to bind the APP, scan the QR code to find a suitable shared express package and a shared express website for short-distance use, place an order and customize, and select payment methods and service location and other relevant and accurate information. The manufacturer uses the platform information to send the order to the distributor. Distributors provide express delivery services to consumers through logistics companies. After consumers use shared packaging boxes, they will put recycled packaging boxes into recycling boxes within a specified time (Figure 9), and send real-time information through the mobile APP, so that logistics personnel can confirm the recycling in time. Since the shared express packaging management system is implemented through a shared platform, in the process of shared express packaging and transportation, periodic inspections of packaging storage, transportation conditions, and storage quantities are required to realize that shared packaging can be used by consumers in a timely manner. Complete information can prevent consumers from being unable to use it after payment. 


\section{Conclusion}

"Shared packaging" is not only a new business model in the era of shared economy, but also the design concept of sustainable development. It is a recyclable sharing platform and sharing mechanism based on the principles of co-construction, sharing, and mutual benefit. Expand the scope of application of recyclable packaging while realizing the principle of sharing economy. Therefore, in the context of the Internet and big data, realizing the sharing of packaging resources, maintaining the development of social ecology, promoting consumers' green consumption behavior, and further improving the shared packaging recycling system and the structure of "box sharing" are to achieve sustainability. The only way to achieve sustainability and development.

\section{REFERENCES}

1. On May 19, 2020, the State Post Bureau "Postal Industry Development Statistical Bulletin 2019". http://www.spb.gov.cn/xw/dtxx_15079/202005/t202 00519_2154947.html

2. Chen Yuebo ": Network Marketing Practices" [M], Xi'an: Xi'an Jiaotong University Press, 2012, pages 124-125.

3. Yu Hang,Tian Lin,Jiang Guoyin,Chen Yun.Sharing Economy:Theoretical Construction and Research Progress[J].Nankai Management Review, Volume 21,Issue 6,2018,Pages 37-52.

4. Pricewaterhouse Coopers. The Sharing Economy[EB/OL].2015

http://bwww.pwc.com/us/en/industry/entertainmentmedia/publications/consumer-intelligenceseries/assets/pwc-cis-sharing-economy.pdf.

5. Botsman. R. The Sharing Economy Lacks a Shared Definition[EB/OL]. Fast Company, November 21, 2013. Available at: http://www.fastcoexist.com/3022028/the-sharingeconomy-lacks-a-shared-definition.

6. Botsman, R., and Rogers, R. What's Mine Is Yours: The Rise of Collaborative Consumption[M]. New York, NY: Harper Business, 2010.

7. He Chao, Zhang Jianqi, Liu Heng,Sharing Economy: Research Review and Future Prospects[J], Economic Management, 2018: $191 \sim 208$.

8. Carlson L, Grove SJ, Kangun N.A Content Analysis of Environmengtal Advertising Claims: A Matrix Method Approach[J].Journal of Advertising, 1993, 22, (3): 27 39.

9. De Young R.Recycling as appropriate behavior: a review of survey data from selected recycling programs in Michigan[J].Conservation and Recycling, 1990, 3(4): 253 -266.

10. Dai Xuehong, Huang Mi. Based on the realization of low-carbon design of packaging in the era of lowcarbon economy[J], Packaging Engineering, 2011, Issue 8 (Volume 32), P75-78.
11. June 22, 2020 "Green Packaging Specification for Express

Mail". http://www.spb.gov.cn/zc/flfgjzc 1/202007/t202007 14_2705975.html 